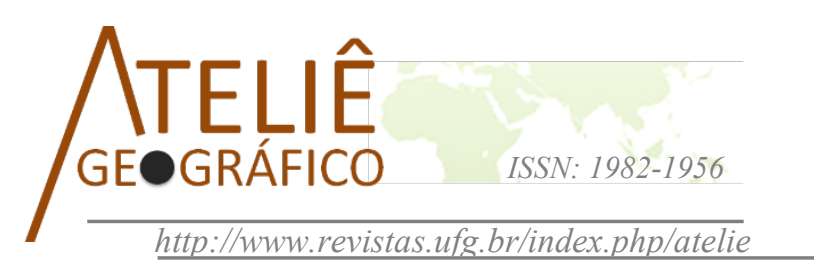

\title{
A construção da temporalidade e as novas sensibilidades em Goiânia: Imaginário e Literatura
}

\author{
The construction of temporality and the new sensitivities in \\ Goiânia: Imaginary and Litertetury
}

La construction de la temporalité et les nouvelles
sensibilités à Goiânia: Imaginaire e Literature

Valéria Cristina Pereira da Silva

Universidade Federal de Goiás

vpcsilva@hotmail.com

\begin{abstract}
Resumo
Goiânia consistiu na experiência de criação da cidade planejada como a transformação espacial, completa e simultânea, independente da diacronia, no contexto do seu surgimento. Contudo, hoje o desenho e mesmo seu plano há muito já se transformaram e não mais correspondem às ideias originais. Buscamos compreender tais transformações a partir da construção da temporalidade que vai alterando o sentido das paisagens, promovendo rupturas com as formas que as engendraram e o surgimento de novas imagens e sensibilidades urbanas, sobretudo advindas da literatura e da arte. A construção da temporalidade opera uma transformação nas paisagens de Goiânia em paisagens imaginárias que surgiram sob o signo de serem formas espaciais, ambientais, urbanísticas, arquitetônicas, artísticas e culturais; inclusive, aquelas advindas de processos preservação do passado e da valorização da memória urbana.
\end{abstract}

Palavras-chave: cidades planejadas, paisagem urbana, poesia

\begin{abstract}
Goiânia was consisted in the experience of creating planned city as a spatial transformation, complete and simultaneous, independent of diachrony in the context of the emergence of this city. However, today the drawing and even their plan have long since been transformed and no longer correspond to the original ideas. In addition to the similarity between these city concerning images and speeches originated from the ways they were made, we look for to understand such transformations from construction of temporality that alter the sense of landscapes, promoting ruptures with the concept of modernity as they engendered and the generation of new images and urban sensibilities. The construction of temporality interrupts the thread of modernity and works a transformation in the landscape of Goiânia, which emerged under the sign of being, a first, administrative capital and today, increasingly, they are also financial and cultural capital. We approach how and
\end{abstract}


what these innovations have invaded in these planned capitals, from the interior of Brazil, that have become contemporary metropolis whose landscapes present new spatial, environmental, urbanist, architectural, artistic and cultural; including those from preserving process from the past and enhancing urban memory.

Keywords: planned city, urban landscape, poetry.

\begin{abstract}
Résumé
Goiânia est représentative de la création de la ville planifiée. Dans le contexte de surgissement de telles villes, la transformation spatiale est complète et simultanée, indépendante de la diachronie. Cependant, aujourd'hui, les dessins et même les plans se sont déjà transformés et ne correspondent plus aux idées originales. Nous chercherons à comprendre, au-delà de la ressemblance entre cet ville dans les images et les discours issus de la manière sont elle furent crée, de telles transformations, et ce à partir de la construction des temporalités qui modifient la signification des paysages, en promouvant autant de ruptures avec le concept de modernité qui les a engendrées que la production de nouvelles images et de nouvelles sensibilités urbaines. La construction de la temporalité rompt le fil de la modernité et opère une transformation dans les paysages de Goiânia, qui furent à l'origine élaborées comme capital administrative et qui aujourd'hui est devenue surtout des capital financière et culturelle. Nous analyserons quelles innovations ont pénétré ces capital planifiée, qui est devenue de métropole contemporaine dont les paysages présent de nouvelles formes spatiales, environnementales, urbanistiques, architecturales, artistiques et culturelles, y compris celles issues du processus de préservation du passé et de la valorisation de la mémoire urbaine.

Mots-clés: ville planifiée, paysage urbain, poésie.
\end{abstract}

\title{
Introdução
}

Nas cidades planejadas há uma dialética entre a duração e o vivido, entre um ano zero, ou seja, o ponto de partida da cidade, que emerge onde nada havia, e as memórias que serão geradas no decorrer desse espaço vivido. A experiência da cidade, ou seja, aquela dos sujeitos que passam a viver nela, começa com um choque: não há lembranças a partir do lugar e a sua história apenas começa. A bagagem que esses protagonistas trazem pode até ser as referências para se começar a construir o vivido da cidade nova, mas não o é ainda porque, a princípio, ninguém lá nasceu. Todos veem de fora e é preciso que decorra ao menos 60 ou 80 anos para que a cidade, novíssima, venha a ter as suas primeiras memórias, sua primeira geração de memorialistas e, portanto, o seu espaço vivido já que este é constituído da experiência e das lembranças no lugar. Goiânia é um exemplo de como esse processo ocorreu nas cidades planejadas brasileiras, a memória urbana vai se constituindo à medida em que o tempo passa e das próprias experiências nele decorridas. Assim, temporalidade, como a qualidade que o tempo imprime nos lugares, também é uma condição para uma cidade que nasce aparentemente "pronta", alargada, inteira no espaço e a partir de um projeto, de uma ação técnica e política. Os projetos, em si mesmos, como foi o caso dos projetos criados por Atílio Correia Lima e Armando Godói para Goiânia, contêm temporalidades outras à medida em que implicam, por exemplo, em citações de referências europeias, conforme apresenta Daher (2003). Ou seja, de algum modo, podemos compreender a existências de temporalidades múltiplas que chegam aos espaços novos, mas ainda não se trata do 
espaço vivido, que é a vivência, a experiência e a memória no próprio lugar e a partir do lugar. $\mathrm{O}$ forjar da cidade planejada causa esse choque e uma colisão perceptiva entre a duração e o vivido que nos convida a pensar nesta dialética e na própria ontologia dessas cidades que está intimamente vinculada a essa condição.

Neste artigo buscamos apresentar como, a partir do imaginário literário, se dá relação entre a temporalidade e sensibilidade na constituição de Goiânia que lhe confere, sobretudo, sua condição ontológica. Compreendemos aqui a ideia de sensibilidade como um conceito que vem sendo reiteradamente apresentado na atualidade por um conjunto variado de autores, com múltiplas filiações teóricas e nuances de sentidos, tais como Rancière (2009), Consiglieri (2007), Canevacci (1998), Mafesoli (1994), Coelho (2011), Harvey (1992), Pesavento (1999. 2008), Olalquiaga (1998). Contudo, de diferentes formas tais autores abordam a importância do sensível e contribuem para a compreensão do que seja o sensível, compondo um quadro teórico de referências que nos permita compreender a sensibilidade como um largo espectro que vai desde os sentidos com os quais somos dotados, tais como a visão, o tato, o olfato, a audição e o paladar, bem como as sensações produzidas por meio desses sentidos, os sentimentos gerados a partir delas e como isso amadurece sob a forma complexa denominação emoção. Tais autores também apresentam o entendimento do mundo contemporâneo e sua percepção como uma nova sensibilidade. Buscamos assim, compreender como percepção e emoção se conjugam com o imaginário na criação obras, na compreensão e na representação da realidade.

Ao tratar da cidade a partir da literatura, observamos que as imagens geradas não são divorciadas da sensibilidade: os sentidos, as sensações e a emoção. Bachelard (1993, 1997), mesmo tecendo claras distinções entre o imaginário, a memória e a percepção, afirma que os poetas são fenomenólogos natos e advoga a favor da imaginação material, ou seja, aquela que maneja e modela as substâncias. "É necessário que uma causa sentimental, uma causa do coração se torne uma causa formal para que a obra tenha a variedade do verbo, a vida cambiante da luz". (BACHELARD, 1997, p.2). Reconhecemos aqui um trânsito profícuo entre a percepção, a geração do sensível e atividade imaginária embora, seguindo, a fenomenologia bachelardiana, concordamos que a imaginação não seja subordinada à percepção; podendo ser fenômenos totalmente independentes, o que não significa que os conteúdos da sensibilidade não colaborem na atividade imaginária.

Na abordagem sobre o imaginário da cidade, Pesavento (1999, p.10) apresentanos que a cidade é uma sensibilidade feita de texto e que "o escritor como espectador privilegiado do social, exerce a sua sensibilidade para criar uma cidade do pensamento" (PESAVENTO, 1999, p.10). Desse modo, para compreender as relações entre as sensibilidades e temporalidades de Goiânia, será realizada uma análise fenomenológica a partir das narrativas literárias e poéticas que primeiro imaginam a cidade e depois a representam. Seguiremos a fenomenologia de Gaston Bachelard (1993) como principal corpo teórico-metodológico nesta jornada interpretativa, pois ela fornece as bases para a discussão do espaço vivido, a ontologia do espaço e o imaginário via criação literária, ou seja, todos os principais elementos que contemplam essa investigação, bem como as distinções entre imaginação, memória e percepção. Na perspectiva de Bachelard (1989, 
p.19), os sonhos e as fantasias não se modernizam tão rápidos como as nossas ações e, para aquele que sonha, o tempo é lento. O tempo aprofunda as imagens e as lembranças se reúnem, o poeta une o que vê ao que viu, conhece a fusão da imaginação com a memória.

Há uma forma de temporalidade na memória e outra na duração. A cidade contém as duas. Nós podemos eleger uma ou outra como objeto de investigação, aqui daremos prioridade para a primeira, o que não significa que a segunda não comparecerá nas reflexões ou no texto literário, porque a cidade planejada, enquanto tema, traz profundamente a questão dessa dialética entre a duração e o vivido. Abordei, em outros trabalhos, Silva (2010a, 2012, 2013) sobre a cidade planejada como "cidade do tempo ausente" numa investigação ontológica da construção de Palmas, capital do Tocantins, assim como a Brasília vista por Clarice Lispector, Silva (2010b). E o que significa tempo ausente? É a ausência de história, de duração ou do vivido? Nem a história, nem a duração, nem o vivido e nem memória fazem parte do espaço, antes que as pessoas vivam, que o tempo escoe e o lugar faça sentido. No máximo, o espaço é preenchido com citações, simulacros, ideias forjadas fora do lugar.

As primeiras manifestações de sentidos, a construção do vivido vem com a conjugação da temporalidade e das sensibilidades e neste sentido, uma das obras fundamentais que será analisada neste trabalho é a antologia poética intitulada: Goiânia Flor e Poesia, obra que consiste numa edição comemorativa dos 60 anos de Goiânia, na qual vários poetas vão homenagear Goiânia e lhe atribuem muitos sentidos decodificando-a como espaço imaginário. Tal obra, Goiânia Flor e Poesia, também será cotejada com outra intitulada Goiânia, 80 anos de poesia. Entendemos que esses poemas sobre a cidade tornam-se monumentos urbanos e revelam sensivelmente o tempo, o vivido e sua ausência desconcertante na origem da própria cidade e de sua imagem ontológica.

A cidade é um lugar afetivo e, quando articulamos nossas escalas subjetivas, temos a casa, o bairro ou setor e a cidade como o conjunto de lugares que frequentamos e cujas paisagens convertem-se em imagens especializadas que farão parte tanto da memória, como do imaginário social. O vivido se cristaliza através da afetividade e da temporalidade. Em Goiânia, a temporalidade urbana está em construção e o tempo do acontecimento perdura sobre a longa duração, seguindo a perspectiva conceitual de Braudel (1992), aqui o acontecimento é o que existe em detrimento da longa duração.

A cidade como o lugar que pertencemos é o espaço em que tanto se sucede os locais como escoa dentro de nós o tempo. Aprendemos dela as suas mudanças, assim como as nossas próprias transformações. Ao percorrer os textos literários que se ocuparam de Goiânia como fonte fundamental desse imaginário, na dialética entre a duração e o vivido, percebemos que há uma percepção e uma consideração da própria noção dessa ausência da duração e os impactos advindos da construção de uma cidade inteira para ser ocupada. Desse modo, são fundamentais para compreender os conteúdos e os significados da cidade planejada as várias formas de perceber o tempo como duração e passagem e as temporalidades múltiplas, ou seja, as qualidades que, através 
dessa passagem, o vivido deixa no espaço como ação e registro que, paulatinamente, vai constituindo o espaço simbólico. Desse modo, vamos à Goiânia imaginária, a cidade do sertão entre a aridez da realidade e a sedosa plumagem do sonho.

\title{
No caminho do espaço vivido: Goiânia e a literatura
}

A poesia goianiense vai nascendo à medida em que a cidade vai se constituindo. No livro Goiânia Flor e Poesia, uma antologia comemorativa dos 60 anos de Goiânia e que tem como tema esta cidade, observamos que predomina ainda os poemas cujo sentido é o espanto do surgimento da capital, sua transferência, a forma de apreender o tempo como a ontologia do próprio espaço, como nos seguintes versos:

\section{A cidade e os Dias: os prazeres e as horas}

Neste dia de trégua em que tudo pode ser

Melhor porque tudo nele é certeza

De que existe toda uma vida pela frente, Como é bom que você e eu existimos

Em algum lugar sonhando construindo, fazendo e refazendo

O mundo nas mãos e a vontade de dominar o tempo

E dando-nos ao luxo de esquecer

Que a maior riqueza é o instante

Que passa, simplesmente porque

Você tem domínio absoluto de cada momento.

(SAMPAIO, Adovaldo Fernandes. In: Goiânia Flor e Poesia: 1993, p.14).

\section{Goiânia}

\author{
A Babel das balbúrdias \\ E das harmonias urbanísticas! \\ Brinquedo gigante de meninos grandes! \\ Improvisação de gênios... \\ Sonho ousado de homens que não recuam... \\ Cidade improvisada para Glória! \\ Marco da Civilização nas fronteiras do Futuro!
}

(MORBACH, A. Bastos. In: Goiânia Flor e Poesia: 1993, p.17. $1^{\circ}$ lugar no concurso de poesia da Revista Oeste em 1944). 


\section{ABC de Goiânia - Posse de Goiânia}

No seu primeiro ideal

Traçado com esforço

Foi mudar a capital

De um verdadeiro calabouço

(MARIANO, Adolfo. In: Goiânia Flor e Poesia: 1993, p.10).

É uma tarefa árdua compreender o imaginário, pelo viés da literatura, em uma cidade do tempo ausente porque essas representações vão se constituindo a conta-gotas e nem sempre são constituídas com grandes nomes e obras, mesmo assim é o que nos chega às mãos como documento e monumento na perspectiva traçada por Le Goff (2003, p.526), para o qual o documento é escolha do pesquisador e o monumento é herança apresentando-se como tudo aquilo que pode evocar o tempo e a recordação. Por exemplo, os versos acima, presentes na coletânea reúnem os melhores poemas de 1903 a 1993, inclusive as poesias premiadas no conjunto dessas primeiras décadas em concursos elaborados por órgãos e entidades locais, essa obra tem tanto as qualidades de documento como de monumento, pois trata-se de uma visão da cidade naquele momento presente, como também representa uma memória para o futuro.

A percepção dessas primeiras seis décadas vem em forma de poemas, ora com conteúdo ufanista, ora crítico, havendo abundância do primeiro em detrimento do segundo. Desse modo, em meio a tais particularidades, as impressões significativas sobre a cidade de Goiânia coagulam em torno dos mesmos sentidos: o tempo visto como instante e futuro, a cidade como sonho e improviso, uma Babel sem passado como nos versos acima. Observamos nestas obras que a maioria representa o surgimento da cidade como um sonho, como se não fosse possível desprender-se ainda do onirismo da sua construção e fixar-se na sua realidade. Destacamos que, independente do quilate literário de um poema ou do poder de suas imagens, ou mesmo do reconhecimento do autor, outrora notabilizado regionalmente, as imagens e sentidos repetem-se.

No que corresponde ao gênero poesia, que, como afirma Bachelard (1993), se trata da literatura em profundidade, ou seja, aquele em que a imaginação perscruta os caminhos mais vastos e longínquos da alma humana para criar imagens que uma fenomenologia vem por evidência; e, na poesia, Goiânia surge à percepção dos poetas como um espaço sem lembranças e um sonho de futuro, portanto, como uma luva pelo avesso, uma casa sem telhado ou ainda um buraco símbolo: 


\section{Sinos e flores}

Bronzes repicam pela cidade.

Telhas símbolos voam

De cada lar para a revoada

De sonhos pássaros

Em melodia de orquestra de flores.

O buraco-símbolo dos telhados

Recebe o perfume e o som [...]

Martelos-construtores de acordes

Completam a melodia.

(SPÍNDOLA, Alice. In: Goiânia Flor e Poesia: 1993, p.20).

Outra imagem preponderante do imaginário da Goiânia planejada é da própria cidade plantada no sertão, presente também no Hino a Goiânia:

Vinde ver a cidade pujante, Que plantaram em pleno sertão!

Vinde ver este tronco gigante,

De raízes profundas no chão!

Construída com esforço de heróis

É um hino ao trabalho e à cultura,

E seu brilho a qual mil sóis

Se projeta na vida futura.

(FLEURY, João Luciano Curado \&. RAMOS, Anatole - Música e Letra. In: Goiânia Flor e Poesia: 1993, p.21).

Ele vê no largo plaino brotarem as sementes

Que se plantou, de barro e cal, em claros dias.

Sublevam as formas sólidas e cúbicas

Em réplica às maquetes do sonho

E um suspiro evade-se de seus lábios.

(SPÍNDOLA, Alice. In: Goiânia Flor e Poesia: 1993, p.20). 
$\mathrm{Na}$ impressão de uma estranha e incompreendida modernidade, a cidade planejada surge como uma forma vegetante em meio ao vazio. Tais imagens perduram ao longo dos poemas como uma essência de Goiânia, na dialética entre a cidade e sertão, entre a modernidade e o atraso. A poesia mais crítica, como a de Brasigóis Felício, não renuncia à metáfora agropastoril, como no poema Boiás, O Berço Esplêndido

[...] Na terra em que se plantando

Tudo dava, todo dia

É dia do Fico. Boiás é curral elitoral

Do eminente babão com sua

Mania de mandão.

Em Boiás tem muita fome,

Mas o plantio é geral

Boiânia é o paraíso dos invocados

Iluminados pelo pó do césio,

O azul da Prússia, e de outros pós-tudo. [...]

Nós somos os novos boianos,

Filhos diletos

Destes sacis expertos

De que falou o Gilberto.

(FELÍCIO, Brasigóis, Alice. In: Goiânia Flor e Poesia: 1993, p.29-31).

Denúncia e sátira são qualidades inextrincáveis desse poema que substitui Goiás e Goiânia por Boiás e Boiânia fazendo aflorar as mazelas das oligarquias familiares que se perpetuam no poder e o resultado dessa política personalista do Estado e da Capital. Felício (1993) também faz uma citação a outro grande poeta Goiano Gilberto de Mendonça Teles e sua obra Saciologia Goiana, a qual também dedica um poema a Goiânia que é replicada também em Goiânia Flor e Poesia:

\section{Goiânia}

Um dia alguém subiu a serra, Gostou de ver o sol nascendo e falou:

"Goiás, capital Goiás" não fica bem.

Nem para o ensino de geografia

Nem para a cultura atlântica do Rio de Janeiro 
E tratou logo de escolher

No meio do cerrado

$\mathrm{O}$ local mais adequado

à construção

de uma cidade que tivesse a pinta da revolução 30 .

Da terra vermelha e dura

Meio escondida pelo capinzal

De repente nasceu a planta-arquitetura

Da Nova Capital

De ruas claras de largas avenidas [...]

Uma planta arquipoética

Sobre o triângulo dos rios

que se levantam do mapa e se projetam

no espaço mítico da cidade $[. .$.

(TELES, Gilberto de Mendonça. In: Goiânia Flor e Poesia: 1993, p.59-61).

A poesia de Teles é marcada pelo que denominamos de geograficidade, ou seja, uma qualidade do geográfico inscrita na impressão dos lugares, nos jogos com a toponímia, na crítica revestida de ironias aos quadros políticos que tangenciam a cidade de Goiânia. Neste poema, Gilberto de Mendonça Teles envia-nos diretamente à cidade e expressa o imaginário da Goiânia planejada a identidade arquipoética e mítica da construção. De acordo com (Bussato, 2007, p. 11), Gilberto apresenta "as franjas telúricas da palavra", em tal imersão telúrica traz crenças, lendas, mitos de fundação que aprofundam a ontologia de Goiânia e o contexto do seu surgimento técnico-mágico e ao mesmo tempo folclórico que estampam o mapa da cidade. A geopoética do mito de que o triângulo formado pelas avenidas radiosas do centro da cidade consistiriam no manto de Nossa Senhora, a arquipoética a nutrir a imagens mágicas e sagradas que começavam a brotar deste espaço tornando a própria paisagem, miragem, aparição vinculando ao ser no lugar, como nas formulações do heidegerianas apresentadas por Holzer (1998).

Os poemas registram numa espécie de cartório poético a geograficidade e sua claridade sublinha o dito em detrimento do não-dito, os graus de silêncio, no jogo delicado das palavras, torna-se silensual, como diria Teles (2007, p.213), enquanto ourives da palavra que faz a paisagem ser muito mais do que as imagens que o olhar abarca, circunscreve também sentidos que irradiam sobre cidade.

Goiânia, a nova capital planejada, de planos sofisticados e sem tempo, jovem cidade de poucas memórias, a única coisa "arcaica" cantada por Gilberto é a poética de seus planos, que o olhar do sertanejo verá símbolos para além da cartografia. Uma constelação de ideias circunscritas num recorte limitado de imagens. 
É importante salientar que autores regionais, através da literatura, encontram as primeiras imagens que figuraram como chaves para a constituição do sentido de Goiânia e entre jogo de aparências, efemeridades, ufanismos, lugares comuns. Entre a crítica e o elogio, fazem emergir essências do lugar para além das entrelinhas e do silêncio no vazio do tempo, a representação de uma essência da cidade no emergir do mito como uma dimensão secreta, incontida no sujeito que habitaria a cidade. Assim, a literatura como fonte que evidencia a sensibilidade do olhar sobre a paisagem e o imaginário em formação configura também como os fios dessa identidade em construção. Poemas elogiosos e afetivos revelam um itinerário perceptivo e emocional sobre o lugar e aí residem sua importância. Com o objetivo de fixar imagens essenciais, muitos autores detêm-se no espaço urbano de Goiânia trazendo paisagens e sentidos e, até mesmo, redesenha com palavras os traços fundamentais do plano da cidade, como observamos nestas duas poesias concretas:

\title{
Adaglion Aires de Andrade GOIÂNIA VIVA
}

\author{
Entre rodas faiscantes \\ e a penumbra do ermo, \\ a poeira brotou com \\ desejo de garras eternas \\ dos sonhos Ludoviquianos.
}

Cascos e cascalhos rolaram do onírico

e desfilaram na

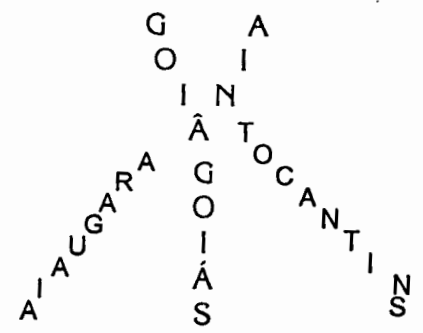

Goiânia, 19 de agosto de 1993

Figura 01: Poesia concreta: Goiânia Viva de Adaglion Aires de Andrade.

Fonte: GOMES V. L.O. (org.), Goiânia Flor e Poesia, 1993, p. 9). 


\section{Edmar Guimarães}

\section{MANTO CONCRETO}<smiles>CC(C)OC(=O)OCCOC#N</smiles>

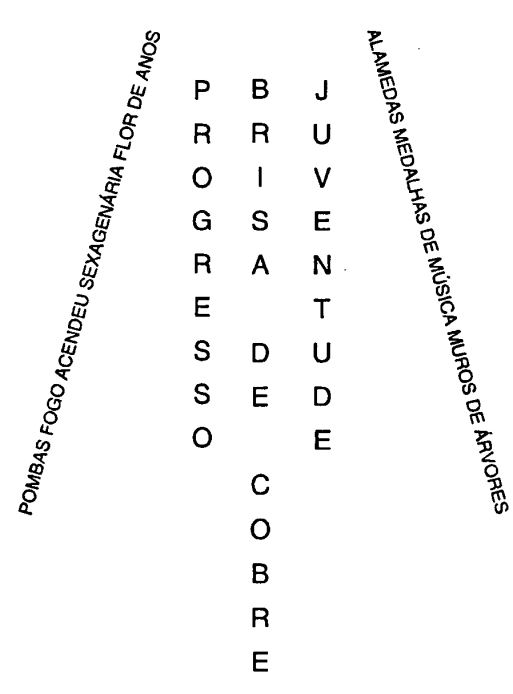

RIO ME-IA PONTE

\section{PASSOS DOS BANDEIRANTES}

Figura 02: Poesia concreta: Manto Concreto de Edmar Guimarães.

Fonte: GOMES V. L.O. (org.). Goiânia Flor e Poesia, 1993, p.43).

Os poemas desenham iconicamente com palavras o mapa do centro da cidade, suas ruas e seu simbolismo e ligam-se ao mito de fundação de Goiânia gerado pelo povo e que constitui a "planta arquipoética" tal qual apresenta Teles (1993) no poema Goiânia e nos permite afirmar que, partindo dessa antologia poética reunida ao longo dos primeiros 60 anos de Goiânia, nos deparamos com as imagens que começam a constituir o imaginário da cidade. Um dos fortes pontos de convergência dessas imagens é a relação entre o plano urbano de Goiânia ter sua imagem associada ao manto e à imagem de Nossa Senhora Aparecida como alude o poema Manto Concreto de Edgar Guimarães, ou mesmo o onirismo evocado por Adaglion Aires em Goiânia Viva. Sobre essa visão mítica da cidade, Mello (2006) apresenta-nos que a significação é atribuída em oposição completa aos dados objetivos, pois segundo a autora, o núcleo central de Goiânia 
desenvolveu-se sob o predomínio de um traçado historicista advindo do urbanismo francês e que o próprio Atílio Correia Lima, arquiteto autor do plano, teria declarado que adotara o partido clássico de Versailles, Carlsruhe e Whashington e o conteúdo simbólico atribuído pelo urbanista estaria ligado apenas à função política da cidade, enquanto centro administrativo.

A conotação político-administrativa e a inspiração em Versalhes, Karlsruhe e Washington são aspectos praticamente desconhecidos da população urbana como um todo, ou seja, em toda a sua escala social. Para o goianiense, o traçado do centro da cidade foi elaborado de modo a configurar a silhueta de Nossa Senhora Aparecida. A forma do segmento urbano em questão evoca uma carga semântica muito distante da pretendida oficialmente.[...] A similaridade com a figura da santa é favorecida pelo pate d'oie ou "pé de pato", nome dado ao recurso de desenho urbano que faz convergir três avenidas para um centro comum. Esse desenho forma um perímetro triangular que corresponde ao manto e a praça circular à cabeça de Nossa Senhora Aparecida (MELLO, 2006, p.51).

Assim, de acordo com Mello (2006, p. 63), o goianiense insiste em ver no plano versalhesco de Goiânia o manto da virgem e o Centro Administrativo, atualmente Palácio Pedro Ludovico Teixeira, onde se situa a cabeça da santa que, geograficamente, constitui-se na associação do político e do religioso como força simbólica do espaço central de Goiânia. É de se considerar que tal imaginário se vincula às próprias heranças e tradições dos sujeitos que vão habitar esse espaço. O estado de Goiás é marcado por uma forte identidade religiosa que se multiplica em festas, procissões, ritos, mitos, cores e cantos e as mais diversas manifestações do sagrado. Como conceber, considerando tais tradições e crenças, que a nova cidade tenha no seu centro um palácio administrativo no lugar que o imaginário reserva a uma igreja ou catedral? Como afirma Bachelard (2013, p, 38), na modernidade que põe luz em todos os cantos, o inconsciente não se civiliza e ainda apanha uma vela para descer ao porão. Essa imagem mito-poética de Goiânia também nasce da força de contrários exercida pelo choque entre a tradição e a modernidade. A modernidade de Goiânia vai de encontro com a tradição do estado de Goiás de diferentes modos, refletindo-se também na literatura, a antinomia metrópole e sertão, tradição e modernidade vão configurando o imaginário, os modos e os gestos. Chaveiro (2011, p.13), por exemplo, afirma que Goiânia é uma metrópole onde o catchup e a pamonha encontram-se e que, portanto, é uma metrópole em travessia; essa travessia, que talvez possamos compreender como entretempo da cidade, ou as suas imagens no trânsito na construção da temporalidade. A cidade, assim, abarca uma profusão de paisagens, de palavras de sentidos em consolidação pela argamassa do imaginário social que literatura ajuda a mapear em sua invenção e revelação. 


\section{Goiânia: uma ontologia do sonho}

A dimensão onírica da cidade planejada é outro elemento constante nos poemas e narrativas, assim Goiânia é a cidade sonho ou faz parte das cidades dos sonhos, conforme Chaul e Duarte $(2005)^{1}$, re-citada em poesia e interpretada em diversas obras literárias e mesmo científicas devido ao caráter espantoso do seu surgimento. Tal dimensão onírica também dá a ela uma atmosfera enigmática, pois surge inteira, pronta, completa sem o lastro misterioso no pergaminho do tempo, em seu espaço ondula formas riscadas de silêncios e ausências. O tecido imaginário de Goiânia vai bordando os signos no qual o mais singelo poema os retêm numa contida constelação, em quase todos os poemas dedicados a esta capital, referem-se a ela como a cidade-sonho, é uma imagemsonho e esse onirismo, ora celebrado, ora rechaçado, cria impressionantes imagens como a indelével narrativa de viagem de Levi-Strauss (2004) que marcaria Goiânia:

«Visitei Goiânia em 1937. Uma planície sem fim, que lembrava um terreno baldio e um campo de batalha, espetado por postes de eletricidade e por fixas de agrimensura, deixava entrever uma centena de casas novas espalhadas pelos quatro quantos do horizonte [...] nada podia ser tão bárbaro, tão desumano, quanto essa implantação no deserto. Essa construção sem graça era o contrário de Goiás; nenhuma história, nenhuma duração, nenhum hábito lhe saturava o vazio ou lhe suavizara a rigidez; ali nos sentíamos como numa estação de trem ou num hospital, sempre passageiros e nunca residentes. Só o receio de um cataclismo podia justificar aquela casamata. De fato, produzira-se um, cuja ameaça era prolongada pelo silêncio e pela imobilidade reinantes. Cadmo, o civilizador, semeara os dentes do dragão. Numa terra esfolada e queimada pelo sopro do monstro, esperava-se para ver os homens crescerem.» (LEVI-STRAUSS, 2004, p.118, grifos nossos)

O olhar de Levi-Strauss na década de 1930 revela exatamente essa angústia de presenciar o canteiro de obras da implantação de uma cidade inteira. As palavras de Levi-Strauss ainda hoje acompanham o imaginário da cidade de Goiânia. Mello (2006, p33) interpreta a dura percepção do antropólogo como choque entre a cidade e o sertão, mas também como a construção de Goiânia foi vista como um ato de violência, pois "isso significava que não se podiam erguer cidades de forma abrupta, sem que antes se estabelecesse 'alguma história', ou seja, 'alguma duração'[...] sem que o hábito ou a vivência ajudassem a esculpir a paisagem” (MELLO, 2006, p. 33). Observamos também que ele assinala em seu texto que Goiânia era o contrário da Cidade de Goiás por não ter duração, vivência que lhe saturasse o vazio, ou seja, uma cidade sem a expressão do vivido e isso gerara as palavras dramáticas, mas perfeitamente compreensíveis, de LeviStrauss (2004), sobretudo no trecho em destaque podemos compreender e conjecturar

1 Ver Oliveira. E C. de. As imagens de Goiânia na literatura Mudancista. In: CHAUL Nars, Fayd e DUARTE Luiz Sérgio (org.). As cidades dos sonhos, 2005. 
que no imaginário social de Goiânia começa, então, sem as marcas do vivido, pela leva de passantes e migrantes que aqui chegaram e a viram, portanto, desumanizada, pelo seu vazio, pela forma artificializada e programática, pelo descampado chão vermelho de sua construção.

Uma outra referência literária para compreender esse surgimento de Goiânia é a obra o Chão Vermelho de Eli Brasiliense, publicado em 1956. A obra tem como principal personagem a própria cidade de Goiânia, a transformação ocorrida neste espaço, sobretudo no que corresponde à transição do rural para o urbano, a cidade nascente e seu aspecto, ao mesmo tempo de colmeia e canteiro de obras, com homens trabalhadores vindos de todas as regiões do país.

\begin{abstract}
«[...] as casas todas olhando para um rumo só. Eram casas desordenadas no mato ralo da campina de terra vermelha. Havia ainda residências brotando do charravascal, em setores novos, naquela terra podre que desmoralizava os construtores apressados, rachando paredes e desconjuntando alicerces. Pouca gente conhecia a verdadeira história da mudança da capital para Goiânia, num pedaço de chão considerado sem serventia [...] (BRASILIENSE, 2002, p. 43-44).
\end{abstract}

O livro narra o espetáculo de surgimento da cidade e entre o espanto e a admiração, as paisagens vão tecendo-se ao longo das páginas assim como o imaginário sertanejo das pessoas que passam a habitá-la. O paradoxal lugar surgido da prancheta dos arquitetos, com inspiração e ideais europeus, e sua ocupação por mulheres e homens sertanejos, míticos e profundos que trarão para as ruas de Goiânia uma linguagem própria, talvez única no Brasil, uma marchetaria de sentidos, falas, de costumes, de tempos lentos e rápidos, conforme aborda Santos (2001), e de gestos que faz de Goiânia uma metrópole que nasce sob o estigma de cidade sertaneja.

Toninho olhou a cidade lá embaixo, os flamboyants em floração, as avenidas em movimento intenso. Espantou-se por vê-la tão crescida. Havia bairros que não conhecia ainda, por falta de tempo. A cidade já engolia o tempo, esmagava o indivíduo com a sua população de mais de oitenta mil viventes. O carro parou em frente a esquina do Botafogo, a pedido dele [...] (BRASILIENSE, 2002, p.134, grifos nossos).

A identidade em construção é uma intrincada marchetaria nesta cidade onírica, em que as tradições e o universo simbólico dos sujeitos fundem-se ao cenário urbano e moderno e, ao mesmo tempo em que seduz, é uma incógnita na paisagem. 


\section{"Ode a Goiânia"}

Goiânia, um silo de indagações

alimenta o rebanho de dúvidas

no estabular sossego dos enigmas

Ainda assim, Goiânia,

Um sutil sonho nos adere

Como os liames secretos

De um istmo íntimo...

(LOURENÇO, E. «Ode a Goiânia». GOMES (org.),

Goiânia Flor e Poesia, 1993, p.40-42)

Edival Lourenço traz, nesse poema, uma síntese do imaginário que irá emergir em muitos outros autores. O poema sublinha essa dimensão do sonho que circunda a cidade como "fluidez de gás" e, ao mesmo tempo em que a apresenta como "máquina de moer motivos", reconhece o tempo urbano como uma tenda de sentimentos nômades. Tudo é passageiro, há problemas, pessoas que morrem e moram na praça, o rio que atravessa a cidade está esquartejado, Goiânia é uma "urbe hard e rude", uma "trágica flor de carne viva". O trajeto de afirmações e indagações presentes na antologia poética de Goiânia culminam também na configuração dos liames secretos da cidade e na percepção de que se trata de um espaço de enigmas.

\section{Goiânia entre o espaço e tempo: uma paisagem imaginária}

Falar de uma cidade que contém a temporalidade oferece-nos um conteúdo mais denso e diversificado para abordá-la. Quanto maior for a duração de uma cidade, mais o vivido satura-lhe o espaço. Já na jovem literatura goianiense há uma fixação no registro do advento da cidade e como ela já se configurava logo em sua inauguração pois, "A Goiânia do ano zero era povoada por cavalos, homens e bicicletas. Hoje, remodela seu trânsito, reforma suas avenidas, exige mais espaço". (CHAUL, 1998, p.165).

Goiânia teve sua paisagem bastante transformada rapidamente em apenas oito décadas e meia, sua expansão expressiva superou surpreendentemente o que havia sido estabelecido como plano urbano, ou seja, a cidade rompeu rapidamente o seu traçado para metamorfosear-se de uma cidade de cinquenta mil habitantes no espaço metropolitano de um milhão e meio nessa curta duração.

Em diversas passagens da literatura goianiense deparamo-nos com a busca pela temporalidade e a percepção de um tempo zero atrelado ao tempo rápido da transformação da paisagem. Na literatura, observamos a percepção de que a nova paisagem urbana, sob a égide da modernidade, apaga os traços materiais do passado goiano, ou seja, ficando esses traços apenas no patrimônio imaterial, como por exemplo, as cenas dos carros de bois que ainda trafegavam por Goiânia no canteiro de obras da cidade, como parte da tradição do povo goiano, fora desaparecendo da paisagem. A 
construção de uma nova temporalidade com seus sentidos e angústias, bem como a dialética entre modernidade e tradição, são também traços do imaginário da cidade.

O poema Outubro ou Nada de Pio Vargas (2010), também presente na antologia Goiânia Flor e Poesia, joga com a expressão "tudo ou nada" que pode ser a pista de um primeiro sentimento do habitante dessa urbe. Apostar e viver nesta cidade que surgiu do nada é, em parte, entrar no jogo e arriscar-se. No primeiro bloco de estrofes vemos imagens da cidade muito simbólicas como uma cidade vista por uma janela do tempo que irá construir-se a partir de um outubro qualquer, tudo é possibilidade, há uma ameaça de não concretizar-se, de ser apenas uma miragem no abruto caos dos relógios, uma ilusão, até o silêncio dos monumentos denuncia essa condição. O silêncio é signo da dor e da saudade de um futuro ameaçado, porque o eterno é só o momento. Como se Goiânia só pudesse ser narrada pelas páginas de uma história ainda a ser escrita, vamos de encontro ao enigma. Os livros e jornais ainda não foram escritos, a cidade, verdadeiramente, nesse momento não foi escrita pela história:

\title{
Outubro ou nada
}

\author{
Goiânia, \\ foi-me dado \\ o direito de falar contigo, \\ não pela língua dos jornais \\ ou dos livros, \\ mas pela janela deste outubro \\ que nos ameaça com seus olhos \\ de futuro \\ e a dor das flâmulas boiando \\ nos flamboyants... \\ não direi dos pêndulos \\ dos vincos \\ de Pedro Ludovico \\ inscrito no silêncio dos monumentos \\ (o eterno da história é o momento). \\ II \\ venho ó Goiânia \\ vestir o intestino \\ de tuas ruas desertas \\ e abastecer as viagens \\ do olhar dos andaimes [...]
}


venho avistar-me
habitante urbano
de teus enigmas;
supor a notícia nova
nos anais de teu sangue
abrir-se num sonho [...]

venho, sobretudo, no disfarce pretérito dos projetos:

goiânia é alguém se gerando

no abrupto caos dos relógios.

[...]a exata dimensão

do peso nos ombros

(dos rombos)

e das cordas do relógio

ruflando nos biombos do peito?

de nossas praças [...]

\section{IV}

Goiânia, há muito que dizer, mas eu fecho os olhos

pra recordar a última voz

de teu silêncio:

"eu vim do milagre

de fluir entre a memória e o futuro".

(efêmero é o poema que tente desnudá-la Goiânia).

(VARGAS, 2010, p. 191-195).

Há uma tentativa de capturar a paisagem, buscar o sentido nas ruas desertas, compor memórias e compreender o tempo gerando-se no invólucro do novo. O habitante dessa urbe tem um triplo papel, construir-se a si mesmo, a cidade e sua história geralmente um lugar em que todos são migrantes, pois quando a cidade surge, ninguém, até então, nascera lá - construir a cidade, a sua história, já que ela se efetiva verdadeiramente no futuro. $\mathrm{O}$ exímio poema na tentativa de desvendar-lhe o sentido desnuda o enigma; os relógios neste contexto são imagens que simbolizam o tempo e a busca inquietante pela sua passagem que figura como uma marca do inconsciente coletivo, impressa na paisagem urbana de Goiânia. Os relógios multiplicam-se pela cidade como um emblema na paisagem em importantes monumentos, marcando no viver a obsessão pelo tempo cronológico e medido da modernidade representado pelo relógio, em choque com o tempo demiúrgico, conforme (Silva, 2013). Na dialética entre a duração e o vivido, os relógios são imagens que alimentam também o mito do progresso. 
A literatura traz nas suas representações imaginárias o contraste entre visão do habitante que ocupa esse espaço, a modernização transformadora de formas, hábitos e gestos e a ausência de identidade. Sobre essa questão, Mello (2006) afirma que, embora a cidade não seja assunto preferido dos cronistas, um dos temas mais abordados é o seu crescimento deletério, tema este que também está presente tanto na obra $O$ Chão Vermelho, como na antologia poética de Goiânia. Identifica-se também a ausência de identidade do lugar, pois a capital foi transferida, assim como a própria literatura foi transferida para Goiânia, a princípio ela não nasce goianiense, mas vem com a tradição literária sedimentada na antiga capital desde 1867, de acordo com Teles (1964). Tais escritores, poetas, porém, pousaram sua sensibilidade sobre a nova capital, entre o assombro e o fascínio de vê-la surgir, deitaram a pena para sublinhar que Goiânia também fora feita de "argamassa espiritual", como afirma Teles (2010, p.12). A literatura fora muito importante nesse sentido, de atribuir significação à cidade na ausência do vivido, na fragilidade da temporalidade e da identidade, nesse sentido, até o nome da capital fora forjado a partir da literatura, Lima (2013) afirma que Goiânia foi uma cidade inventada, que foi batizada com nome de livro:

o livro de nome Goyania é um poema épico de 20 cantos, publicado em 1986, escrito por Manuel Lopes de Carvalho Ramos [...] ela "permaneceu, durante dois anos, no âmbito legal, inominada [...]Antes de ter nome de livro, foi cidade sem nome, era apenas a nova capital. (LIMA, 2013, p. 62).

Sobre esse fato também Mello (1996, p. 37) afirma que Goyânia, nome inventado e retirado do poema épico, foi sugerido por Alfredo de Faria Castro, figura ilustre, professor e poeta na cidade de Goiás, também conhecido pelo pseudônimo de Caramuru do Brasil. Assim, a literatura decodifica os sentidos e traz imagens que formam uma trama imaginária da qual a cidade se alimente. Na nova coletânea Goiânia 80 de poesia de Caldeira e Brito (2013), muitos novos autores se fazem presentes, vários dos nomes consagrados se fazem presente tais como Gilberto de Mendonça Teles, Gabriel Nascente, Pio Vargas, Brasigóis Felício, entre outros e em meio a 95 autores que dedicam à cidade um poema ou uma narrativa. Contudo, a maior parte das imagens e sentidos permanecem as mesmas, Goiânia continua sob o signo da construção entre a argamassa e sonho.

\section{Conclusão}

A construção da cidade de Goiânia significou uma grande ruptura na paisagem local e, além disso, sofreu rapidamente transformações que foram alterando os seus sentidos, a temporalidade em construção promove rupturas com as formas que a engendraram, assim como promovem também surgimento de novas imagens e sensibilidades, sobretudo, plasmadas na literatura. Porém, ainda vigora com bastante força uma Goiânia imaginária atrelada ao poder dos seus planos, a força pulsante de sua criação. Na maior parte dos poemas analisados, foi possível identificar os seguintes elementos: o olhar reiterado sobre essa paisagem em construção e transformação, a 
percepção de uma temporalidade inexistente, ou seja, a cidade surgida divorciada do vivido e que começa a transcorrer lentamente. Uma angústia em relação à compreensão desse espaço, seus significados e sua identidade, a dialética entre a modernidade e a tradição, a cidade e o sertão e ainda a cidade vista de forma onírica. O ruído do espaço no silêncio tempo, dialética entre o tempo do acontecimento, Braudel (1992) portanto, rápido, e o tempo lento do escoamento e ainda a dialética entre a duração e o vivido. É importante lembrar também que não há vivido sem alguma duração, já que vivido pressupõe passado. Quando Bachelard (1993, p.18) tece a sua crítica, a duração bergsoniana, ele o faz analisando uma poética que mal matiza as lembranças, então o que importa não é a duração em si mesma, mas o vivido, a matéria lembrada, imaginada no interior da duração.

O tempo ausente dá também a dimensão enigmática da cidade e o enigma é o vazio do próprio vivido que desliza entre o sonho e a aridez da construção. Assim, esse tempo caótico, tempo do porvir, faz com que o futuro seja sempre cantado nos poemas. A cidade ainda não teve o seu grande cronista, aquele que vai capturar no cotidiano seu jeito de ser, que vai buscar na miríade a sua essência em novas imagens. A cidade espera aquele escritor que fale dos guarda-chuvas pintados em seus muros e do rumor de suas avenidas e que consiga ver novas e outras imagens ocultas em seu seio de pedra. A cidade nasceu do sertão, mas com grã-finos planos importados, fez-se metrópole moderna, com sociedade moderna, pós-moderna e contemporânea, mas o mundo ainda não a viu. A imagem da cidade continua um sonho que repete-se em busca de um despertar e que constitui a própria ontologia da cidade. Desse modo, a maior construção da cidade é ainda a construção simbólica e para a qual ela se alimenta de tempo e do vivido para se constituir, mesmo que o seu espaço seja uma realidade metropolitana indelével.

Milhares de pessoas percorrem seus trajetos diariamente num extenso mapa metropolitano, circulam no seu centro, trafegam já congestionando sua trama radiosa, avistam e atravessam a Praça Cívica várias vezes transformada, requalificada; ruas são abertas, novas edificações são inauguradas, shoppings centers emergem todo o seu tecido, novos grupos estéticos surgem em seu território... Mas que significados todo esse conjunto tem? Por que a ontologia da cidade contínua vinculada à sua gênese, se há muito esse espaço já fora transformado em outro? Há uma nova sensibilidade em curso? As nossas perguntas esperam pelos poetas, como esperam pelo tempo.

\section{Referências}

ANDRADE, A. A. Goiânia Viva in GOMES, V. L. O. (Org.), Goiânia flor e poesiaantologia poética, Goiânia: Secretaria de Cultura, Esporte e Turismo: Núcleo de Patrimônio Histórico e Artístico, 1993, pp. 9.

BACHELARD, G. A água e os sonhos: ensaio sobre a imaginação da matéria. São Paulo: Martins Fontes, 1997.

BACHELARD, G. A poética do espaço. São Paulo: Martins Fontes, 1993. 
BACHELARD, G. A chama de uma vela. Rio de Janeiro: Bertrand Brasil, 1989. BRASILIENSE, E. O chão vermelho. Goiânia, IGL/AGEPEL, 2002.

BRAUDEL, F. - «A longa duração.». História e Ciências Sociais. Lisboa, Editorial Presença, 1992.

BUSATTO, L. A trepidação vital de Gilberto. In: TELES, Gilberto de Mendonça. Melhores poemas. São Paulo: global, 2007, p.7-14.

CALDEIRA, U., BRITO, E. Goiânia: 80 anos de poesia. Goiânia: IHGG/Kelps, 2013.

CANEVACCI, M. A cidade polifônica: ensaio sobre a antropologia da comunicação. São Paulo: Studio Nobel, 2004

CHAVEIRO, E. F. Goiânia Reinventada. Goiânia: PUC-GO/Kelps, 2011.

CHAUL, N. F. Os caramujos contemporâneos da modernidade. Goiânia, Edição do autor/ABDR, 1998.

CHAUL N., F. DUARTE L. S. (Org). As cidades dos sonhos: desenvolvimento urbano em Goiás. Goiânia: UFG, 2005.

COELHO, T. Moderno pós-moderno. São Paulo: Iluminuras, 2011.

CONSIGLIERI, V. As metáforas da arquitetura contemporânea. Lisboa: Editorial Estampa, 2007.

DAHER, T. Goiânia, uma utopia europeia no Brasil. Goiânia, ICBC, 2003.

GALLI, U.; BRITO E. C. Goiânia: 80 anos de poesia. Goiânia: IHGG/Kelps, 2013.

GOMES, V. L. O. (Org). Goiânia flor e poesia - antologia poética. Goiânia, Secretaria de Cultura, Esporte e Turismo. Núcleo de Patrimônio Histórico e Artístico, 1993.

HOLZER, W. Um estudo fenomenológico da paisagem e do lugar: a crônica dos viajantes no Brasil do século VI. 1998. 257 f. Tese (Doutorado em Geografia) Faculdade de Filosofia Letras e Ciências Humanas - USP - São Paulo 1998.

LÉVI-STRAUSS, C. Tristes Trópicos. São Paulo, Cia das Letras, 2004.

LIMA, A. P. de. Romancidade: sujeito e existência em leituras geográfico-literárias nos romances a Centopéia de Neon e os Cordeiros do Abismo. 2013. 235 f. Tese de Doutorado. (Doutorado em Geografia) - Instituto de Estudos Sócio-ambientais - IESA, Universidade Federal de Goiás, Goiânia.

HARVEY, D. Condição pós-moderna. São Paulo: Edições Loyola, 1992.

LE GOFF, J. História e memória. Campinas: Editora da Unicamp, 1992.

LOURENÇO, E., Ode a Goiânia, in GOMES, V. L. O. (Org.), Goiânia flor e poesia antologia poética, Goiânia: Secretaria de Cultura, Esporte e Turismo: Núcleo de Patrimônio Histórico e Artístico, 1993, pp. 40-42. 
MANSO, Celina Fernandes Almeida. Goiânia, uma concepção urbana, moderna e contemporânea: um certo olhar. Goiânia: Edição do autor, 2001.

MAFESOLI, M. O Elogio da razão sensível. Petrópolis, RJ: Vozes, 1998.

MELLO, M. M. de. Goiânia: cidade de pedras e de Palavras. Goiânia, UFG, 2006.

SANTOS, M. O tempo nas cidades. Rev. Coleção documentos - Estudos sobre o tempo, n. 2, p. 21-22, fev. 2001.

SILVA, V. C. P. da. Palmas, a última capital projetada do século XX: uma cidade em busca do tempo. São Paulo, Cultura Acadêmica, 2010a.

SILVA, V. C. P. da. As cidades do tempo ausente: Brasília vista da crônica de Clarice Lispector». SILVA, M. A. da, SILVA, H. R. F. da (ORG.) Geografia, literatura e arte: reflexões. Salvador, EDUFBA, 2010b. p. 187-198.

SILVA, V. C. P. da. Palmas - entre Pasárgada e Paris: metáforas da cidade imaginária. In: FILHO, G. S., SANTOS, R. S. Ensaios de Geografia e História do Tocantins.

Palmas, Nagô, 2012. P. 180-201.

SILVA, V. C. P. da. Goiânia: um mosaico imaginário: modernidades e micro-tempoterritorialidades. Rev. Caderno Prudentino de Geografia. Presidente Prudente, n. 35, volume especial, p.6-25, 2013. Disponível em:

http://revista.fct.unesp.br/index.php/cpg/issue/view/223/showToc . Acesso em: 25 de agosto de 2018.

TELES, G. de M. Saciologia Goiana. Goiânia, AGEPEL, 2001.

TELES, G. de M. Melhores poemas. São Paulo: global, 2007.

TELES, G. de M. Goiás e literatura. Goiânia: Edições E.T.G, 1964.

TELES, J. de M. Goiânia: coração do Brasil. São Paulo, Cortez, 2010.

OLALQUIAGA, C. Megalópolis: sensibilidades culturais contemporâneas. São Paulo: Studio Nobel, 1998.

PESAVENTO, S. J. "Sensibilidade no tempo, tempo das sensibilidades” In: Colóquio Nuevo Mundo, Mundos Nuevos, n. 04, 2004. Disponível em http://nuvomundo.revue.org/documento229.html. Acesso em 25 de março de 2008.

PESAVENTO, S. J. O imaginário da cidade: visões literárias do urbano. Porto Alegre: UFRGS, 1999, 393 p.

PESAVENTO, S. J. O imaginário da cidade: visões literárias do urbano. Porto Alegre: UFRGS, 1999

RANCIÈRE, J. A partilha do sensível: estética e política. São Paulo: Editora 34, 2009.

VARGAS, P. Poesia Completa. Goiânia: R\&F, 2010. 
*Este trabalho consiste em resultados do projeto em desenvolvimento intitulado "De cidades planejadas à metrópoles contemporâneas: novas sensibilidades urbanas e transformações na paisagem em Goiânia, Brasilia e Belo Horizonte", com financiamento do CNPq.

\section{Valéria Cristina Pereira da Silva}

Pós-doutora pela Universidade Nova de Lisboa-Faculdade de Ciências Sociais e Humanas - NOVA FCSH - junto ao IELT - Instituto de Estudos de Literatura e Tradição. É doutora em Geografia pela Universidade Estadual Paulista - Unesp Campus de Presidente Prudente SP. É docente da Universidade Federal de Goiás no Instituto de Estudos Socioambientais-IESA.

Av. Esperança, s/n - Samambaia, Goiânia - GO, 74001-970.

Email: vpcsilva@hotmail.com

Recebido para publicação em agosto de 2018 Aprovado para publicação em abril de 2020 